\title{
Active Distribution Grid Management based on Robust AC Optimal Power Flow
}

\author{
Soares, Tiago; Bessa, Richard J.; Pinson, Pierre; Morais, Hugo
}

Published in:

IEEE Transactions on Smart Grid

Link to article, DOI:

10.1109/TSG.2017.2707065

Publication date:

2018

Document Version

Peer reviewed version

Link back to DTU Orbit

Citation (APA):

Soares, T., Bessa, R. J., Pinson, P., \& Morais, H. (2018). Active Distribution Grid Management based on Robust AC Optimal Power Flow. IEEE Transactions on Smart Grid, 9(6), 6229 - 6241.

https://doi.org/10.1109/TSG.2017.2707065

\section{General rights}

Copyright and moral rights for the publications made accessible in the public portal are retained by the authors and/or other copyright owners and it is a condition of accessing publications that users recognise and abide by the legal requirements associated with these rights.

- Users may download and print one copy of any publication from the public portal for the purpose of private study or research.

- You may not further distribute the material or use it for any profit-making activity or commercial gain

- You may freely distribute the URL identifying the publication in the public portal

If you believe that this document breaches copyright please contact us providing details, and we will remove access to the work immediately and investigate your claim. 


\title{
Active Distribution Grid Management based on Robust AC Optimal Power Flow
}

\author{
Tiago Soares, Ricardo J. Bessa, Pierre Pinson, Senior Member, IEEE, Hugo Morais, Member, IEEE
}

\begin{abstract}
Further integration of distributed renewable energy sources in distribution systems requires a paradigm change in grid management by the distribution system operators (DSO). DSOs are currently moving to an operational planning approach based on activating flexibility from distributed energy resources in day/hour-ahead stages. This paper follows the DSO trends by proposing a methodology for active grid management by which robust optimization is applied to accommodate spatial-temporal uncertainty. The proposed method entails the use of a multiperiod AC-OPF, ensuring a reliable solution for the DSO. Wind and PV uncertainty is modeled based on spatial-temporal trajectories, while a convex hull technique to define uncertainty sets for the model is used. A case study based on real generation data allows illustration and discussion of the properties of the model. An important conclusion is that the method allows the DSO to increase system reliability in the real-time operation. However, the computational effort grows with increases in system robustness.
\end{abstract}

Index Terms - Decision-making; uncertainty; distribution system operator; robust optimization; solar power; wind power.

\section{NOMENCLATURE}

The main notation used throughout the paper is stated next for quick reference. Other symbols are defined as required.

\section{A. Parameters}

$\begin{array}{ll}\Delta P & \text { Power deviation of the vertices of the uncertainty set } \\ \eta_{C h}, \eta_{D c h} & \text { Charge and discharge efficiency } \\ B & \text { Imaginary part in admittance matrix } \\ \text { Bus } & \text { Number of buses } \\ C & \text { Cost } \\ E_{\text {BatCap }} & \text { Maximum capacity of energy storage systems } \\ E_{\text {Min }} & \text { Minimum energy in the energy storage system } \\ G & \text { Real part in admittance matrix } \\ N & \text { Number of unit resources } \\ T & \text { Time horizon } \\ \bar{y} & \text { Series admittance of line that connects two buses } \\ \bar{y}_{\text {sh }} & \text { Shunt admittance of line that connects two buses }\end{array}$

\section{B. Variables}

$\begin{array}{ll}\theta & \text { Voltage angle } \\ E_{\text {stored }} & \text { State of charge of the battery } \\ P & \text { Active power } \\ Q & \text { Reactive power } \\ r & \text { Power flexibility used in the real-time stage } \\ S & \text { Apparent power }\end{array}$

\begin{tabular}{|c|c|}
\hline$V$ & Voltage magnitude \\
\hline $\bar{V}$ & Voltage in polar form \\
\hline$V_{s b}$ & Voltage at slack bus \\
\hline$\Delta V$ & Voltage level activated by the DSO in the transformer \\
\hline$X$ & Binary variable \\
\hline \multicolumn{2}{|c|}{ C. Subscripts } \\
\hline$c b$ & Index of capacitor bank units \\
\hline$C B$ & Capacitor bank abbreviation \\
\hline Ch & Storage charge process \\
\hline Dch & Storage discharge process \\
\hline$d g$ & Index of distributed generation units \\
\hline$D G$ & Distributed generation abbreviation \\
\hline$D R$ & Demand response abbreviation \\
\hline$i, j$ & Bus index \\
\hline l & Index of load consumers \\
\hline$L$ & Load consumers abbreviation \\
\hline lv & $\begin{array}{l}\text { Index of levels (tap changing) for capacitor banks and } \\
\text { transformers }\end{array}$ \\
\hline$p v$ & Index of photovoltaic power units \\
\hline$P V$ & Photovoltaic power abbreviation \\
\hline$s$ & Index of the vertices of the uncertainty set \\
\hline st & Index of energy storage system units \\
\hline su & Index of external supplier units \\
\hline$S U$ & External supplier abbreviation \\
\hline$t$ & Time index \\
\hline $\operatorname{trf}$ & Index of transformer units \\
\hline$T R F$ & Transformer abbreviation \\
\hline$w$ & Index of wind power units \\
\hline$W$ & Wind power abbreviation \\
\hline \multicolumn{2}{|c|}{ D. Superscripts } \\
\hline act & Activation cost of resources in real-time stage \\
\hline bid_dw & Maximum offer of downward flexibility \\
\hline bid_up & Maximum offer of upward flexibility \\
\hline cut & Generation curtailment power for distributed generation \\
\hline$d w$ & Downward flexibility \\
\hline op & Operating point of the power resource \\
\hline shed & Load shedding \\
\hline spill & Spillage of renewable energy \\
\hline up & Upward flexibility \\
\hline
\end{tabular}

\section{INTRODUCTION}

HE continuous integration of distributed energy resources
(DER) [1], specially renewable energy resources (RES), at 
the distribution grid level will lead to the development of new models and methodologies to deal with the uncertainty of these resources [2]. Hence, traditional methodologies for operation and management of the distribution grid must be replaced by new active management methodologies, by which distribution system operators (DSOs) can contract/control power generation/consumption (flexibility) from DER to solve congestion/voltage problems in the distribution network [3].

An ideal approach would be to accommodate all traditional distribution grid management methods with new proactive management methods adapted to future distributions systems that include DER controllability to help in grid management. For instance, problems concerning network reconfiguration, voltage limit violation and overcurrent during short periods can be added to the proactive management method.

Currently, DSOs in most European countries employ a reactive approach for grid management, imposing limits in terms of DER (mainly RES) integration in MV and LV levels. For instance, a survey applied under an EU project in several European countries showed that very few DSOs use the forecasts for operational purposes, as well as, contracting services to handle network constraints [4]. Furthermore, the degree of coordination between DER and the DSO control centers is very limited or non-existent in almost all countries.

The flexibility potential from DER (including flexible operation/bids from RES) requires a change in the present paradigm. The trend is to implement proactive and preventive grid management functions based on forecasts with the possibility of reserving/controlling DER connected to the distribution grid. The goal of the DSO remains the same, i.e. to ensure that congestion, voltage and energy delivery problems are solved, while maintaining the proper operation of the system with adequate levels of safety, reliability and power quality. Under high RES integration levels, this goal can be met by combining multi-period optimal power flow (OPF) with uncertainty forecasts.

Most of the literature proposals for the distribution grid management problem are based on stochastic methods with relaxation approaches to the OPF. However, DSOs usually operate under the premise of procuring a solution or scenario that ensures proper levels of robustness and reliability in the system. The regulatory framework "induces" risk aversion to both the DSO and transmission system operator.

In this context, several methodologies have emerged for distribution grid management considering RES uncertainty. These methodologies are most often based on stochastic programming and robust optimization [5], [6]. A decentralized stochastic approach to manage a distribution network with PV production is proposed in [7]. However, the model only ensures effectiveness under radial networks. In [8], a stochastic method based on chance-constrained optimization for voltage control under PV uncertainty production is proposed, however, the method considers a probabilistic load flow that analyses the injection of PV power in the distribution system. The authors in [9] consider a point-estimate method to deal with wind uncertainty and a probabilistic OPF. However, the output from the stochastic OPF is a distribution of the decision variables. Nevertheless, for a DSO, a more appropriate output would be a single solution that is robust in all or a pre-defined percentage of the scenarios. Within this scope, robust OPF approaches should be taken into account. A robust DC OPF using quadratic programming with successive constraint enforcement is proposed in [10]. Similarly, [11] proposes a robust DC OPF using conditional value-at-risk to mitigate the risk of wind power in the system. As a proper analysis of distribution systems requires the modeling of an AC OPF, [12] proposes a robust AC OPF where the AC power flow constraints are relaxed through second-order cone programming. For an in-depth discussion on recent advances and developments in AC OPF and its application to smart grids, interested readers are referred to [13] and [14], respectively.

In contrast to the literature, this paper contributes with a new methodology based on robust optimization for solving technical problems in the distribution network under RES forecast uncertainty, ensuring a single and safe solution that is more reliable than traditional approaches. The model minimizes the operating costs (flexibility activation) of the DSO, without relaxing any network constraints under a set of spatial-temporal trajectories. The methodology is proposed for a paradigm whereby the DSO preventively manages the distribution grid by contracting flexibility from DER in advance based on forecasted information. This is a recent trend in the scientific community [15]-[17]. Thus, the DSO will have more flexibility capacity to use in real-time operation, thereby increasing the safety and reliability of the system. This work has two major contributions to the state of art: (a) integration of spatial-temporal trajectories [18] to model RES, while using convex hull based techniques to model the uncertainty set; (b) active distribution grid management in a multi-period AC OPF, which is able to ensure the most reliable solution for the distribution grid.

The paper is structured as follows. Section II describes the DSO management problem with a perspective on current and future trends. Section III presents the detailed formulation of the robust approach for the DSO problem on energy resources management under uncertainty. Section IV describes our empirical investigation based on a case study with real data. Section V gathers the most important conclusions.

\section{FRAMEWORK FOR DistRIBUTION GRID MANAGEMENT}

\section{A. Current Management}

The mission of a DSO is to ensure the quality and continuity of supply levels imposed by the regulatory framework. In the past, technical problems such as overcurrent and voltage limit violation were mitigated by planning network investments and changing the network configuration to meet the loads. Now, DSOs have additional flexibility in the network that allows them to solve the local technical problems in the operational domain, instead of solving them in a planning phase. The main benefits are investment deferral and reduced curtailment of DER.

In the operating domain, the typical control actions are network reconfiguration, control of capacitor banks and 


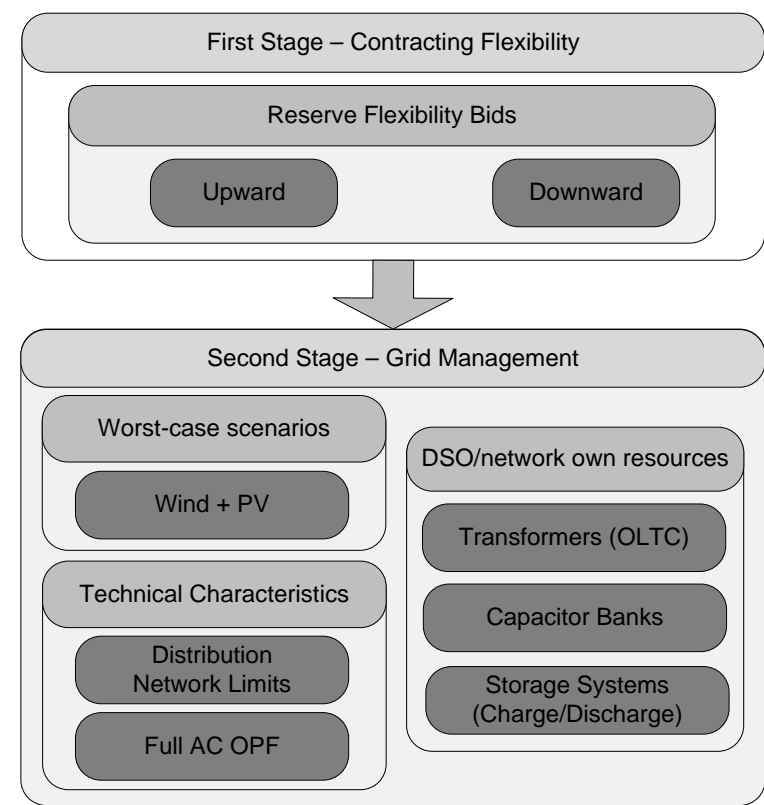

Fig. 1. Diagram of the developed methodology.

activation, though in a very limited way, of non-firm connection contracts associated with industrial loads and some DER. Information about forecasts and corresponding uncertainty is not embedded in the current grid-management functions.

Nevertheless, the use of DER flexibility to help in the management of technical problems is of most interest to the DSO. The DER flexibility stands for the amount of power provided by the DERs that assist the DSO in grid management. This means that is a kind of ancillary services, but used by the DSO to solve congestion and voltage problems in the distribution system. As proposed in this work, a better use of DER flexibility can delay or even avoid the need for network expansion. That is, the DSO can use power flexibility provided by DERs to decongest the main power lines/transformers and control the voltage levels in the distribution grid. This gives a certain control freedom to DSO grid management. However, a long-term evaluation is recommended to estimate the savings of the proposed method in the system. Such economic savings must be compared with equivalent costs of network reinforcement to assess the usefulness of the proposed method in long-term.

\section{B. Future Management}

With the continuous introduction of DERs, DSOs have been changing their operation and control paradigms. Thus, fully proactive grid management, by which DERs can be part of the solution for proper operation of the distribution system, is considered. However, RES are part of the problem since they have uncertain generation, thereby increasing the system operation uncertainties. Nevertheless, current developments in wind power technology mean that, to some extent, it is possible to reserve the available wind power to provide power flexibility [19]. In fact, field-tests with the real provision of ancillary services (such as frequency restoration reserves) from renewable power plants performed in Germany [20] and Belgium [21] have demonstrated that it is possible to provide reserve capacity with acceptable accuracy. In this way, future
DSO management should integrate new methodologies to deal with RES uncertainty while considering this new capability of RES, as well as considering energy storage systems to help the DSO solve congestion problems and efficiently deliver energy [4].

A new structure for solving technical problems in the distribution grid is illustrated in Fig.1. The structure is divided into two stages is used: (i) contract of upward and downward flexibility services from DER at day-ahead time-horizon; and (ii) distribution grid management considering the flexibility contracted in the first stage and internal resources of the distribution network, accounting for the worst-case of uncertainty in the system.

The first stage (day-ahead stage) is based on contracting upward and downward flexibility to be used during the realtime stage (second stage) to manage the grid and solve congestion problems, accounting with the uncertainty of renewable sources. In the first stage, upward and downward flexibility bids, respectively given by $P^{\text {bid_up }}$ and $P^{b i d \_d w}$, from the DER aggregators are provided to the DSO. The DSO contracts the flexibility to the DER aggregators based on capacity payments. It is noteworthy that wind and PV aggregators should guarantee the provision of the submitted upward and downward flexibility. For instance, by contracting generators or demand response electrically close to their point of power production. The DER aggregators provide to the DSO the flexibility bids of changing the operating point of their own resources for upward and downward power. The flexibility bids are defined based on the strategy of each aggregator to provide flexibility to the DSO. Wind and PV aggregators can define their bids based on expected profit from supplying this upward and downward flexibility to the DSO, accounting for the costs for changing their operating point [22].

In the real-time stage (second stage), the DSO manages the grid considering the flexibility contracted at day-ahead and the operating point of each DER, as well as its own internal flexibility under the limitations of the technical characteristics of the grid. We understand DSO internal flexibility as the use of static equipment, such as transformers with on-load tapchanging (OLTC) ability, capacitor banks and storage systems. Storage systems owned or managed by the DSO help in the system management, providing additional multi-period flexibility and avoiding constrained situations. Additionally, the storage system contributes to reduce the impact of uncertain production on the system by absorbing or injecting power in cases of surplus or deficit of renewable generation.

Nevertheless, the DSO may contract all the flexibility needed to cover foreseen distribution network problems, considering RES uncertainty and accounting for the economic efficiency of the process. That is the flexibility contracted should be optimized at least cost. Moreover, the core of the methodology lies on the use of a two-stage robust optimization approach to accommodate RES uncertainty, while providing solutions with high reliability levels.

\section{METHODOLOGY}

The methodology is based on robust optimization to model RES uncertainty and solve the DSO management problem. 


\section{A. Uncertainty Set Definition}

Robust optimization requires the definition of uncertainty sets, e.g. vertices representative of the worst-case solution, as explained in [23]. Uncertainty sets can take different forms, for instance, constructing the uncertainty set through a polyhedral, ellipsoid or scenario set with spatial-temporal correlation is the most common in literature, among others [24].

In our proposed methodology, construction of the uncertainty set is modeled through a scenario set with spatialtemporal correlation. The methodology entails some assumptions. For simplicity, the uncertainty modeled in the methodology refers only to wind and solar power. Thus, the load profile for the next 24 hours is assumed to be known. Furthermore, note that spatial-temporal correlation is modeled in scenario generation for wind and solar power independently. This means that uncertain variables for wind and solar power are independent of each other.

The uncertainty sets for wind and PV generation are constructed using a scenario set. The scenario set $J$ is obtained through the generation of spatial-temporal trajectories (or scenarios). For each period, the deviation between the scenario set and the conditional mean forecast creates a cloud of $N_{J}$ points representative of the uncertainty space. Then, the uncertainty set $\Omega$ is defined as the convex hull of these points constructed through the quickhull algorithm [25]. The vertices $u$ of the uncertainty set $\Omega$ that are selected for the optimization process are represented by $\Delta P_{w(w, t, s)}$ in the full problem formulation. In addition, the number of vertices of the convex hull can increase significantly when considering a large amount of intermittent resources, which can be intractable in the time frame available to the DSO to solve the problem. Thus, algorithms to reduce the number of vertices can be considered. The recursive Douglas-Peucker algorithm [26] is based on polyline simplifications and can reduce the number of vertices that characterize the uncertainty set. An improved and accelerated version of the algorithm [27] can be used to significantly reduce the vertices of the uncertainty set.

\section{B. General Problem Formulation}

The problem relates to minimizing the operating costs of the DSO. A multi-period and multi-stage robust optimization problem is modeled. In the first stage (day-ahead stage), the DSO contracts the flexibility to the DER to be used in the second stage (real-time operation), where the power system is operated under the uncertainty of the renewable energy resources. In the second stage, the DSO manages the distribution system based on the worst-case of the uncertainty. Thus and based on the flexibility contracted at day-ahead, the DSO is prepared to manage the grid under any realization of wind and solar power covered by the uncertainty set. Similar problems are commonly solved in the literature using multistage robust optimization techniques [5], [23]. A general form of the robust optimization problem is expressed as

$$
\min _{x} \sum_{t}^{T} C_{t}^{D A}(x)+\max _{u} \min _{y} \sum_{t}^{T} C_{t}^{R T}(y)
$$

$$
\begin{array}{ll}
\text { s.t. } & A_{t}^{D A}(x) \leq 0, \\
& h_{t}^{R T}(y, u)=0, \\
& g_{t}^{R T}(x, y, u) \leq 0,
\end{array}
$$

where the vector $x$ includes the day-ahead decision vectors for contracting flexibility, while real-time adjustments with respect to the contracted flexibility are included in the vector of recourse variables $y$, accounting for the vertices $u$ of the uncertainty set $\Omega$, i.e. $u \in \Omega$. $C_{t}^{D A}(x)$ stands for the cost function of contracting flexibility in day-ahead that composes the objective function of the first-stage. On the other hand, $C_{t}^{R T}(y)$ is the cost function of operating the distribution system in real-time that composes the recourse function. All the constraints involving only first-stage variables are modeled in the form of (2). In contrast, constraints including recourse variables are divided into equalities (3) and inequalities (4).

\section{Full Mathematical Formulation}

This section starts by presenting and explaining the full objective function and respective constraints of the first-stage problem, followed by the full objective function and constraints relating to the recourse stage. It is noteworthy that the problem is modeled as a mixed-integer nonlinear optimization problem, by comprising a full AC OPF model.

The first-stage decisions comprise the flexibility contracted by the DSO in the day-ahead market, where the objective function $C_{t}^{D A}(x)$ is modeled as

$$
\begin{aligned}
& \sum_{d g=1}^{N_{D G}}\left(C_{D G(d g, t)}^{u p} P_{D G(d g, t)}^{u p}+C_{D G(d g, t)}^{d w} P_{D G(d g, t)}^{d w}\right)+ \\
& \sum_{W=1}^{N_{W}}\left(C_{W(w, t)}^{u p} P_{W(w, t)}^{u p}+C_{W(w, t)}^{d w} P_{W(w, t)}^{d w}\right)+ \\
& \sum_{p v=1}^{N_{P V}}\left(C_{P V(p v, t)}^{u p} P_{P V(p v, t)}^{u p}+C_{P V(p v, t)}^{d w} P_{P V(p v, t)}^{d w}\right)+ \\
& \sum_{l=1}^{N_{L}}\left(C_{D R(l, t)}^{u p} P_{D R(l, t)}^{u p}+C_{D R(l, t)}^{d w} P_{D R(l, t)}^{d w}\right) \quad \forall t \in\{1, \ldots, T\} .
\end{aligned}
$$

The decision variable vector $x$ considers the first-stage variables

$x=\left\{P_{D G}^{u p}, P_{D G}^{d w}, P_{W}^{u p}, P_{W}^{d w}, P_{P V}^{u p}, P_{P V}^{d w}, P_{D R}^{u p}, P_{D R}^{d w}\right\}$.

The first-stage constraints considering the upper bound of upward and downward flexibility offers for DG units (2a) and (2b), respectively, are given by

$$
\begin{aligned}
& P_{D G(d g, t)}^{u p} \leq P_{D G(d g, t)}^{b i d \_u p} \quad \forall t \in\{1, \ldots, T\}, \forall d g \in\left\{1, \ldots, N_{D G}\right\}, \\
& P_{D G(d g, t)}^{d w} \leq P_{D G(d g, t)}^{b i d d} \quad \forall t \in\{1, \ldots, T\}, \forall d g \in\left\{1, \ldots, N_{D G}\right\} .
\end{aligned}
$$

In addition, wind and PV aggregators are modeled with the ability of upward and downward flexibility, i.e. it is assumed that wind power producers can provide some flexibility [19]. The wind power for downward flexibility is constrained by the operating point of the wind power aggregator $P_{W(w, t)}^{o p}$, as in (2c), while the wind power for upward flexibility is constrained by the wind bid for reserving power, as in (2d).

$$
\begin{array}{ll}
P_{W(w, t)}^{d w} \leq P_{W(w, t)}^{o p} & \forall t \in\{1, \ldots, T\}, \forall w \in\left\{1, \ldots, N_{W}\right\}, \\
P_{W(w, t)}^{u p} \leq P_{W(w, t)}^{b i d} \quad \forall t \in\{1, \ldots, T\}, \forall w \in\left\{1, \ldots, N_{W}\right\} .
\end{array}
$$

These constraints are also applied to the PV aggregators. 
Similarly, the upper and lower bounds for the DR aggregators are given by

$$
\begin{array}{ll}
P_{D R(l, t)}^{u p} \leq P_{D R(l, t)}^{b i d_{1} u p} & \forall t \in\{1, \ldots, T\}, \forall l \in\left\{1, \ldots, N_{L}\right\}, \\
P_{D R(l, t)}^{d w} \leq P_{D R(l, t)}^{b i d_{1} d w} & \forall t \in\{1, \ldots, T\}, \forall l \in\left\{1, \ldots, N_{L}\right\},
\end{array}
$$

where $P_{D R(I, t)}^{b i d u p}$ is the maximum amount of load that can be reduced (offer).

The objective function and constraints related to the recourse stage are then described. Following adaptive robust theory, the inner max min problem given by $C_{t}^{R T}(y)$ can be replaced by an auxiliary variable $\beta$ representing the worst-case recourse.

In parallel, looking at equalities constraints from the recourse function (related to $h_{t}^{R T}(y, u)$ in equation (3)), the decision variable vector $y$ contains

$y=\left\{\begin{array}{l}r_{D G}^{u p}, r_{D G}^{d w}, P_{D G}^{c u t}, r_{W}^{u p}, r_{W}^{d w}, \Delta P_{W}, P_{W}^{\text {spill }}, r_{P V}^{u p}, r_{P V}^{d w}, \Delta P_{P V}, P_{P V}^{s p i l l}, r_{D R}^{u p}, r_{D R}^{d w}, P_{L}^{\text {shed }}, \\ P_{D c h}, P_{C h}, P_{S U}, Q_{S U}, Q_{D G}, Q_{L}, Q_{C B}, E_{s t o r e d}, X_{C B}, X_{T R F}, V_{i}, V_{s b}, \Delta V_{T R F}, \theta_{i j}\end{array}\right\}$,

including active and reactive power balance, reactive power consumption, capacitor banks tap-changing, transformers with on-load tap-changing, and energy storage balance. Thus, the active power balance in each bus yields,

$$
\begin{aligned}
& \sum_{d g=1}^{N_{D G}}\left(P_{D G(d g, t)}^{o p, i}+r_{D G(d g, t, s)}^{u p, i}-r_{D G(d g, t, s)}^{d w, i}-P_{D G(d g, t, s)}^{c u t}\right)+ \\
& \sum_{s u=1}^{N_{S U}} P_{S U(s u, t, s)}^{i}+\sum_{s t=1}^{N_{S T}}\left(P_{D c h(s t, t, s)}^{i}-P_{C h(s t, t, s)}^{i}\right)+ \\
& \sum_{w=1}^{N_{W}}\left(P_{W(w, t)}^{o p, i}+\Delta P_{W(w, t, s)}^{i}+r_{W(w, t, s)}^{u p, i}-r_{W(w, t, s)}^{d w, i}-P_{W(w, t, s)}^{s p i l l, i}\right)+ \\
& \sum_{p v=1}^{N_{P V}}\left(P_{P V(p v, t)}^{o p, i}+\Delta P_{P V(p v, t, s)}^{i}+r_{P V(p v, t, s)}^{u p, i}-r_{P V(p v, t, s)}^{d w, i}-P_{P V(p v, t, s)}^{s p i l l, i}\right)+ \\
& \sum_{l=1}^{N_{L}}\left(P_{D R(l, t)}^{o p, i}+r_{D R(l, t, s)}^{u u, i}-r_{D R(l, t, s)}^{d w, i}+P_{L(l, t, s)}^{s h e d, i}-P_{L(l, t)}^{i}\right)= \\
& G_{i i} V_{i(t, s)}^{2}+V_{i(t, s)} \sum_{j \in T L} V_{j(t, s)}\left(G_{i j} \cos \theta_{i j(t, s)}+B_{i j} \sin \theta_{i j(t, s)}\right) \\
& \forall t \in\{1, \ldots, T\}, \forall i \in\left\{1, \ldots, N_{B u s}\right\}, \forall s \in\left\{1, \ldots, N_{S}\right\}, \theta_{i j(t, s)}=\theta_{i(t, s)}-\theta_{j(t, s)}
\end{aligned}
$$

where $P_{W(w, t)}^{o p}$ is the conditional mean forecast of wind producer scheduled at day-ahead market and $\Delta P_{W(w, t, s)}$ is the deviation of wind power production in the vertices from the conditional mean forecast that models the uncertainty set. $P_{S U(s u, t, s)}$ is the energy provided by external suppliers to the distribution system through upstream connections, i.e. the energy that comes from the transmission system to supply the consumption of the distribution network. In parallel, it is assumed that the reactive power balance only considers reactive power provided by DG (CHP) units, external suppliers and capacitor banks, formulated as

$$
\begin{aligned}
& \sum_{d g=1}^{N_{D G}} Q_{D G(d g, t, s)}^{i}-\sum_{l=1}^{N_{L}} Q_{L(l, t, s)}^{i}+\sum_{s u=1}^{N_{S U}} Q_{S U(s u, t, s)}^{i}+\sum_{c b=1}^{N_{C B}} \sum_{l v=1}^{N_{\text {levels }}} Q_{C B(c b, t, s, l)}^{i}= \\
& V_{i(t, s)} \sum_{j \in T L} V_{j(t, s)}\left(G_{i j} \sin \theta_{i j(t, s)}-B_{i j} \cos \theta_{i j(t, s)}\right)-B_{i i} V_{i(t, s)}^{2} \\
& \forall t \in\{1, \ldots, T\}, \forall i \in\left\{1, \ldots, N_{B u s}\right\}, \forall s \in\left\{1, \ldots, N_{S}\right\}, \theta_{i j(t, s)}=\theta_{i(t, s)}-\theta_{j(t, s)}
\end{aligned}
$$

where the reactive power production for DG (CHP) units takes into account the active power production from the day-ahead market, as well as the upward and downward active power flexibility scheduled by the DSO with a fixed $\tan \Phi=0.3$ [28].

$$
\begin{aligned}
& Q_{D G(d g, t, s)}=\left(P_{D G(d g, t)}^{o p, i}+r_{D G(d g, t, s)}^{u p, i}-r_{D G(d g, t, s)}^{d w, i}-P_{D G(d g, t, s)}^{c u t}\right) \tan \phi \\
& \forall t \in\{1, \ldots, T\}, \forall d g \in\left\{1, \ldots, N_{D G}\right\}, \forall s \in\left\{1, \ldots, N_{s}\right\}
\end{aligned}
$$

Furthermore, the reactive power consumption in the system is modeled based on the relation between the total active power consumption and $\tan \Phi$ for each load $l \cdot \tan \Phi$ for each load $l$ is usually assumed as 0.3 [29].

$$
\begin{aligned}
& Q_{L(l, t, s)}=\left(P_{L(l, t)}-P_{D R(l, t)}^{o p}+r_{D R(l, t, s)}^{d w}-r_{D R(l, t, s)}^{u p}-P_{L(l, t, s)}^{\text {shed }}\right) \tan \phi \\
& \forall t \in\{1, \ldots, T\}, \forall l \in\left\{1, \ldots, N_{L}\right\}, \forall s \in\left\{1, \ldots, N_{S}\right\}
\end{aligned}
$$

Furthermore, the reactive power consumption is partly provided by generators and static equipment in the network. Capacitor banks are used to provide reactive power to the transformer, located at the substation. It is assumed that this equipment is owned by the DSO. Traditionally, capacitor banks have levels of reactive power production, and can be modeled as

$$
\begin{aligned}
& Q_{C B(c b, t, s, l v)}=Q_{C B(c b, t, l v)}^{\text {levels }} X_{C B(c b, t, s, l v)} \\
& \forall t \in\{1, \ldots, T\}, \forall c b \in\left\{1, \ldots, N_{C B}\right\}, \forall s \in\left\{1, \ldots, N_{S}\right\}, \forall l v \in\left\{1, \ldots, N_{\text {levels }}\right\}, \\
& \sum_{l v=1}^{N_{\text {levels }}} X_{C B(c b, t, s, l v)}=1 \\
& \forall t \in\{1, \ldots, T\}, \forall c b \in\left\{1, \ldots, N_{C B}\right\}, \forall s \in\left\{1, \ldots, N_{S}\right\} .
\end{aligned}
$$

In addition, transformers with OLTC ability are used to ensure voltage control in the substation. It is assumed that the transformers are owned by the DSO. Thus, the voltage impact of each tap-changing level in the secondary bus of the transformer is known. The tap-changing constraints can be modeled as

$$
\begin{aligned}
& \Delta V_{T R F(t r f, t, s, l v)}=V_{T R F(t r f, t, l v)}^{\text {levels }} X_{T R F(t r f, t, s, l v)} \\
& \forall t \in\{1, \ldots, T\}, \forall s \in\left\{1, \ldots, N_{S}\right\}, \forall \operatorname{trf} \in\left\{1, \ldots, N_{T R F}\right\}, \forall l v \in\left\{1, \ldots, N_{\text {levels }}\right\}, \\
& \sum_{l v=1}^{N_{\text {levels }}} X_{T R F(t r f, t, s, l v)}=1 \\
& \forall t \in\{1, \ldots, T\}, \forall s \in\left\{1, \ldots, N_{S}\right\}, \forall \operatorname{trf} \in\left\{1, \ldots, N_{T R F}\right\}, \\
& V_{s b(t, s)}=V_{s b(t, s)}^{r e f}+\sum_{l v=1}^{N_{\text {levels }}} \Delta V_{T R F(t r f, t, s, l v)} \\
& \forall t \in\{1, \ldots, T\}, \forall s \in\left\{1, \ldots, N_{S}\right\}, \forall \operatorname{trf} \in\left\{1, \ldots, N_{T R F}\right\},
\end{aligned}
$$

where $\Delta V_{T R F(t r f, t, s, l v)}$ is the voltage level that will be activated by the DSO in the transformer unit at slack bus. In parallel, $V_{T R F(t r f, t, l v)}^{\text {levels }}$ depicts all the possible levels available on the OLTC ability of the transformer. Finally, $X_{\operatorname{TRF}(t r f, t, s, l v)}$ is a binary decision variable which defines the activation of the chosen level. Moreover, the battery balance of storage units follows

$$
\begin{aligned}
& E_{\text {stored (st, },, s)}=E_{\text {stored (st, t-1,s) }}+\eta_{C h(s t)} P_{C h(s t, t, s)}-\frac{1}{\eta_{D c h(s t)}} P_{D c h(s t, t, s)} \\
& \forall t \in\{1, \ldots, T\}, \forall s t \in\left\{1, \ldots, N_{S T}\right\}, \forall s \in\left\{1, \ldots, N_{s}\right\}
\end{aligned}
$$

where energy from previous period, and charge and discharge ability are considered.

In parallel, inequality constraints (related to $g_{t}^{R T}(x, y, u)$ in (4)), the decision variable vector $y$ contains 
$y=\left\{\begin{array}{l}r_{D G}^{u p}, r_{D G}^{d w}, P_{D G}^{c u t}, r_{W}^{u p}, r_{W}^{d w}, \Delta P_{W}, r_{P V}^{u p}, r_{P V}^{d w}, \Delta P_{P V}, r_{D R}^{u p}, r_{D R}^{d w}, P_{L}^{\text {shed }}, \\ P_{D c h}, P_{C h}, X_{C B}, X_{T R F}, E_{\text {stored }}, X_{D c h}, X_{C h}, P_{S U}, Q_{S U}, V_{i}, \theta_{i j}, \beta\end{array}\right\}$,

and include operating costs for balancing the system, upper and lower bounds of active and reactive power to the upward and downward flexibility of all energy resources, as well as non-simultaneity of storage devices, transformers and lines capacity, upper and lower bounds of voltage angles and magnitude, and declaration of non-negative variables.

Thus, the inequality constraint for the operating costs for upward and downward flexibility of different aggregators is considered (4a). Aggregators with distributed generation, wind and PV related with uncertainty and DR are modeled as external entities that provide flexibility and information about their resources' electrical location to the DSO. On the other hand, it is assumed that storage units, capacitor banks and transformers with OLTC ability are owned by the DSO, and therefore these resources are modeled to balance the distribution system, with

$$
\begin{aligned}
& \beta_{t} \geq \sum_{d g=1}^{N_{D G}}\left[C_{D G(d g, t)}^{a c t}\left(r_{D G(d g, t, s)}^{u p}-r_{D G(d g, t, s)}^{d w}\right)+C_{D G(d g, t)}^{c u t} P_{D G(d g, t, s)}^{c u t}\right]+ \\
& \sum_{w=1}^{N_{W}}\left[C_{W(w, t)}^{a c t}\left(r_{W(w, t, s)}^{u p}-r_{W(w, t, s)}^{d w}\right)+C_{W(w, t)}^{s p i l l} P_{W(w, t, s)}^{s p i l l}\right]+ \\
& \sum_{p v=1}^{N_{P V}}\left[C_{P V(p v, t)}^{a c t}\left(r_{P V(p v, t, s)}^{u p}-r_{P V(p v, t, s)}^{d w}\right)+C_{P V(p v, t)}^{\text {spill }} P_{P V(p v, t, s)}^{s p i l l}\right]+ \\
& \sum_{l=1}^{N_{L}}\left[C_{D R(l, t)}^{a c t}\left(r_{D R(l, t, s)}^{u p}-r_{D R(l, t, s)}^{d w}\right)+C_{L(l, t)}^{\text {shed }} P_{L(l, t, s)}^{\text {shed }}\right]+ \\
& \sum_{s t=1}^{N_{S T}}\left(C_{D c h(s t, t)} P_{D c h(s t, t, s)}-C_{C h(s t, t)} P_{C h(s t, t, s)}\right)+ \\
& \sum_{c b=1}^{N_{C B}} \sum_{l v=1}^{N_{\text {levels }}} C_{C B(c b, t)}\left|X_{C B(c b, t-1, s, l v)}-X_{C B(c b, t, s, l v)}\right|+ \\
& \sum_{t r f=1}^{N_{T R F}} \sum_{l v=1}^{N_{\text {levels }}} C_{T R F(t r f, t)}\left|X_{T R F(t r f, t-1, s, l v)}-X_{T R F(t r f, t, s, l v)}\right| \\
& \forall t \in\{1, \ldots, T\}, \forall s \in\left\{1, \ldots, N_{S}\right\}
\end{aligned}
$$

where the upper and lower bounds of the activation of active power for DG units considering the upward and downward flexibility are given by (4b) and (4c), respectively, while the generation curtailment power is expressed in (4d), where $P_{D G(d g, t)}^{o p}$ is the operating point of the DG units. This gives

$$
\begin{aligned}
& r_{D G(d g, t, s)}^{u p} \leq P_{D G(d g, t)}^{u p} \quad \forall t \in\{1, \ldots, T\}, \forall d g \in\left\{1, \ldots, N_{D G}\right\}, \forall s \in\left\{1, \ldots, N_{S}\right\}, \\
& r_{D G(d g, t, s)}^{d w} \leq P_{D G(d g, t)}^{d w} \quad \forall t \in\{1, \ldots, T\}, \forall d g \in\left\{1, \ldots, N_{D G}\right\}, \forall s \in\left\{1, \ldots, N_{S}\right\}, \\
& P_{D G(d g, t, s)}^{c u t} \leq P_{D G(d g, t)}^{o p}-r_{D G(d g, t, s)}^{d w}, \\
& \forall t \in\{1, \ldots, T\}, \forall d g \in\left\{1, \ldots, N_{D G}\right\}, \forall s \in\left\{1, \ldots, N_{S}\right\} .
\end{aligned}
$$

In addition, wind and PV aggregators are modeled with the ability of upward and downward flexibility. The wind power for activating upward flexibility is constrained by the wind contracted in the first-stage decision for reserve power, as in (4e), while the wind power for activating downward flexibility is constrained by the downward flexibility contracted in the first-stage decision, as in (4f). When the downward flexibility is insufficient to the meet the DSO requirement, wind spillage can be used, being constrained by (4g).

$$
\begin{aligned}
& r_{W(w, t, s)}^{u p} \leq P_{W(w, t)}^{u p} \quad \forall t \in\{1, \ldots, T\}, \forall w \in\left\{1, \ldots, N_{W}\right\}, \forall s \in\left\{1, \ldots, N_{S}\right\}, \\
& r_{W(w, t, s)}^{d w} \leq P_{W(w, t)}^{d w} \quad \forall t \in\{1, \ldots, T\}, \forall w \in\left\{1, \ldots, N_{W}\right\}, \forall s \in\left\{1, \ldots, N_{S}\right\}, \\
& P_{W(w, t, s)}^{s p i l l} \leq P_{W(w, t)}^{o p}-r_{W(w, t, s)}^{d w}+\Delta P_{W(w, t, s)} \\
& \forall t \in\{1, \ldots, T\}, \forall w \in\left\{1, \ldots, N_{W}\right\}, \forall s \in\left\{1, \ldots, N_{S}\right\} .
\end{aligned}
$$

These constraints are also applied to the PV aggregators. In parallel, the upper and lower bounds for the activation of DR aggregators are given by

$$
\begin{array}{ll}
r_{D R(l, t, s)}^{\text {up }} \leq P_{D R(l, t)}^{u p} & \forall t \in\{1, \ldots, T\}, \forall l \in\left\{1, \ldots, N_{L}\right\}, \forall s \in\left\{1, \ldots, N_{S}\right\}, \\
r_{D R(l, t, s)}^{d w} \leq P_{D R(l, t)}^{d w} & \forall t \in\{1, \ldots, T\}, \forall l \in\left\{1, \ldots, N_{L}\right\}, \forall s \in\left\{1, \ldots, N_{S}\right\}, \\
P_{D R(l, t, s)}^{\text {shed }} \leq P_{L(l, t)} & \forall t \in\{1, \ldots, T\}, \forall l \in\left\{1, \ldots, N_{L}\right\}, \forall s \in\left\{1, \ldots, N_{S}\right\},
\end{array}
$$

where the load shedding is limited by the load in the system. Storage technical limits in each period $t$ combine distinct inequalities constraints. Thus, the storage devices are used to reduce congestion when needed. Furthermore, the cost of using charge and discharge ability is modeled in eq. (4a). It is assumed that the costs for charge and discharge already consider the battery degradation over time [30]. Upper and lower bounds for energy stored in the battery, as well as the charge and discharge limit per storage unit are modeled as

$$
\begin{aligned}
& E_{M i n(s t, t)} \leq E_{\text {stored }(s t, t, s)} \leq E_{\text {BatCap }(s t, t)} \\
& P_{C h(s t, t, s)} \leq P_{C h(s t, t)}^{\operatorname{Max}} X_{C h(s t, t, s)} \\
& P_{D c h(s t, t, s)} \leq P_{D c h(s t, t)}^{M a x} X_{D c h(s t, t, s)} \\
& X_{C h(s t, t, s)}+X_{D c h(s t, t, s)} \leq 1 \\
& \forall t \in\{1, \ldots, T\}, \forall s t \in\left\{1, \ldots, N_{S T}\right\}, \forall s \in\left\{1, \ldots, N_{S}\right\},
\end{aligned}
$$

where the charge and discharge ability of each storage unit cannot occur at the same time, as in (4n). Furthermore, the energy flow from upstream networks is limited through transformers that adapt the voltage level from high voltage to medium voltage. Therefore, the external supplier provides energy to the DSO through these transformers, which results in a constraint considering the upper limit of the transformers, such that

$$
\begin{aligned}
& \left(\sum_{s u=1}^{N_{S U}} P_{S U(s u, t, s)}^{i}\right)^{2}+\left(\sum_{s u=1}^{N_{S U}} Q_{S U(s u, t, s)}^{i}\right)^{2} \leq\left(S_{t r f}^{M a x}\right)^{2}, \forall t \in\{1, \ldots, T\}, \\
& \forall i \in\left\{1, \ldots, N_{\text {Bus }}\right\}, \forall s \in\left\{1, \ldots, N_{S}\right\}, \forall \operatorname{trf} \in\left\{1, \ldots, N_{\text {TRF }}\right\}
\end{aligned}
$$

Similarly, the thermal limit of distribution lines constrains the power flowing from bus $i$ to bus $j$, and vice-versa, such as

$$
\begin{aligned}
& \left|\overline{V_{i(t, s)}}\left[\overline{y_{i j} V_{i j(t, s)}}+\overline{y_{s h(i)} V_{i(t, s)}}\right]^{*}\right| \leq S_{T L}^{M a x} \quad, \overline{V_{i j(t, s)}}=\overline{V_{i(t, s)}}-\overline{V_{j(t, s)}} \\
& \left|\overline{V_{j(t, s)}}\left[\overline{y_{i j}} \overline{V_{j i(t, s)}}+\overline{y_{s h(j)} \bar{V}_{j(t, s)}}\right]^{*}\right| \leq S_{T L}^{M a x}, \overline{V_{j i(t, s)}}=\overline{V_{j(t, s)}}-\overline{V_{i(t, s)}} \\
& \forall t \in\{1, \ldots, T\}, \forall i, j \in\left\{1, \ldots, N_{\text {Bus }}\right\}, \forall s \in\left\{1, \ldots, N_{s}\right\}, i \neq j
\end{aligned}
$$

where the bus voltage magnitude limits are represented by

$V_{\text {Min }}^{i} \leq V_{i(t, s)} \leq V_{\text {Max }}^{i}, \forall t \in\{1, \ldots, T\}, \forall s \in\left\{1, \ldots, N_{s}\right\}$

assuming that the voltage magnitude is fixed and defined by the DSO for the slack bus (upstream bus connection). 
TABLE I: CONSUMERS CHARACTERISTICS.

\begin{tabular}{cc|c|c|c}
\hline \hline \multirow{2}{*}{ Load } & Bus & \multicolumn{3}{|c}{ Active power consumption $P_{L}(\mathrm{~kW})$} \\
& & Max & Mean & Min \\
\hline 1 & 3 & 1190.5 & 734.7 & 429.9 \\
2 & 4 & 1015.6 & 644.5 & 237.0 \\
3 & 6 & 1184.2 & 662.8 & 101.7 \\
4 & 7 & 1259.1 & 777.0 & 453.9 \\
5 & 9 & 1252.4 & 845.5 & 619.9 \\
6 & 10 & 1040.9 & 693.3 & 343.5 \\
7 & 12 & 1030.1 & 635.7 & 371.4 \\
8 & 14 & 1.9074 & 1210.3 & 445.1 \\
9 & 16 & 2598.3 & 1730.6 & 857.5 \\
10 & 18 & 1184.2 & 799.5 & 586.1 \\
11 & 20 & 1184.2 & 662.8 & 101.7 \\
12 & 21 & 1190.5 & 734.7 & 429.2 \\
13 & 23 & 1272.3 & 847.4 & 419.9 \\
14 & 24 & 1252.4 & 845.5 & 619.9 \\
15 & 26 & 1030.1 & 635.7 & 371.4 \\
16 & 28 & 878.8 & 557.6 & 205.0 \\
17 & 29 & 996.1 & 557.5 & 85.5 \\
18 & 31 & 1001.4 & 618.0 & 361.0 \\
19 & 32 & 1011.9 & 674.0 & 333.9 \\
20 & 34 & 1252.4 & 701.0 & 107.5 \\
21 & 36 & 1074.1 & 681.6 & 250.6 \\
22 & 37 & 1030.1 & 635.7 & 371.4 \\
\hline \hline
\end{tabular}

TABLE II: TRANSFORMER AND CAPACITOR BANK CHARACTERISTICS.

\begin{tabular}{lc|c|c|c}
\hline \hline Equipment & $\begin{array}{c}\text { Number of } \\
\text { units }\end{array}$ & $\begin{array}{c}\text { Number of } \\
\text { Tap-changing } \\
N_{\text {levels }}\end{array}$ & $\begin{array}{c}\text { Tap-changing } \\
\text { capacity } \\
V_{\text {TRF }}^{\text {levels }}, Q_{C B}^{\text {levels }}\end{array}$ & $\begin{array}{c}\text { Cost } C_{T R F}, \\
C_{C B} \text { (m.u. } \\
\text { per change) }\end{array}$ \\
\hline Transformer & 2 & 21 & 0.1 p.u. & 0.19 \\
Capacitor Bank & 1 & 5 & 0.2 Mvar & 0.47 \\
\hline \hline
\end{tabular}

TABLE III: ENERGY STORAGE SYSTEM CHARACTERISTICS.

\begin{tabular}{|c|c|c|c|c|c|c|}
\hline Equipment & $\begin{array}{l}\text { Number } \\
\text { of units }\end{array}$ & $\begin{array}{c}\text { Charge } \\
\text { maximum } \\
\text { power } \\
P_{\mathrm{Ch}}^{\text {Max }} \\
(\mathrm{kW})\end{array}$ & $\begin{array}{c}\begin{array}{c}\text { Discharge } \\
\text { maximum } \\
\text { power }\end{array} \\
P_{D c h}^{M a x} \\
(\mathrm{~kW})\end{array}$ & $\begin{array}{c}\text { Capacity } \\
E_{\text {BatCap }} \\
(\mathrm{kWh})\end{array}$ & $\begin{array}{c}\text { Charge } \\
\text { cost } C_{C h} \\
\text { (m.u./kWh) }\end{array}$ & $\begin{array}{l}\text { Discharge } \\
\text { cost } C_{D c h} \\
\text { (m.u./kWh }\end{array}$ \\
\hline ESS & 4 & 150 & 200 & 250 & 0.030 & 0.065 \\
\hline
\end{tabular}

TABLE IV: GENERAL CHARACTERISTICS AND OPERATING POINT FOR DER.

\begin{tabular}{|c|c|c|c|c|c|}
\hline \multirow{2}{*}{ DER } & \multirow{2}{*}{$\begin{array}{c}\text { Number of } \\
\text { units }\end{array}$} & \multirow{2}{*}{$\begin{array}{c}\text { Total installed } \\
\text { power }\end{array}$} & \multicolumn{3}{|c|}{ Operating point $P^{o p}$ (MW) } \\
\hline & & & $\operatorname{Max}$ & Mean & Min \\
\hline CHP & 3 & 2.5 (Mva) & 1.5 & 1.15 & 1 \\
\hline $\begin{array}{l}\text { External } \\
\text { supplier }\end{array}$ & 1 & 20 (Mva) & - & - & - \\
\hline PV & 22 & 7.74 (MWp) & 5.55 & 1.96 & 0 \\
\hline Wind & 2 & 2.5 (MW) & 1.88 & 1.77 & 1.52 \\
\hline DR & 22 & 4.65 (MW) & 0.1 & 0.03 & 0 \\
\hline
\end{tabular}

TABLE V: DER UPWARD AND DOWNWARD FLEXIBILITY AND COSTS.

\begin{tabular}{|c|c|c|c|c|c|c|}
\hline \multirow{2}{*}{ DER } & \multicolumn{3}{|c|}{ Upward cost $C^{u p}$ (m.u./kWh) } & \multicolumn{3}{|c|}{ Downward cost $C^{d w}$ (m.u./kWh) } \\
\hline & $\operatorname{Max}$ & Mean & Min & Max & Mean & Min \\
\hline CHP & 0.15 & 0.10 & 0.05 & 0.09 & 0.06 & 0.03 \\
\hline PV & - & 0.11 & - & - & 0.06 & - \\
\hline Wind & - & 0.10 & - & - & 0.05 & - \\
\hline DR & - & 0.22 & - & - & 0.17 & - \\
\hline
\end{tabular}

TABLE VI: DER ACTIVATION AND CURTAILMENT COSTS.

\begin{tabular}{lc|c}
\hline \hline DER & $\begin{array}{c}\text { Activation cost } \\
C^{\text {act }}(\mathrm{m} . \mathrm{u} . / \mathrm{kWh})\end{array}$ & $\begin{array}{c}\text { Curtailment } C^{\text {cut }} / \text { spillage } C^{\text {spill }} / \\
\text { load shedding } C_{L}^{\text {shed }}(\mathrm{m} . \mathrm{u} . / \mathrm{kWh})\end{array}$ \\
\hline CHP & 0.18 & 0.36 \\
PV & 0.13 & 0.30 \\
Wind & 0.12 & 0.30 \\
DR - load & 0.26 & 0.90 \\
\hline \hline
\end{tabular}

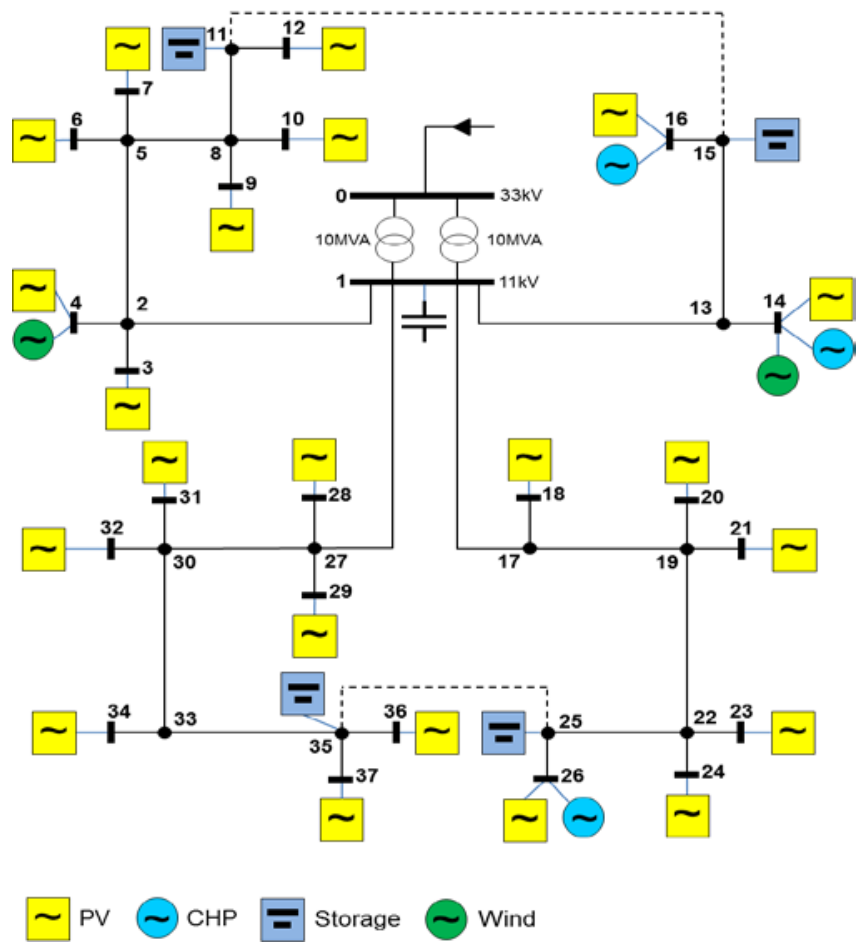

Fig. 2. 37-Bus distribution network (adapted from [32]).

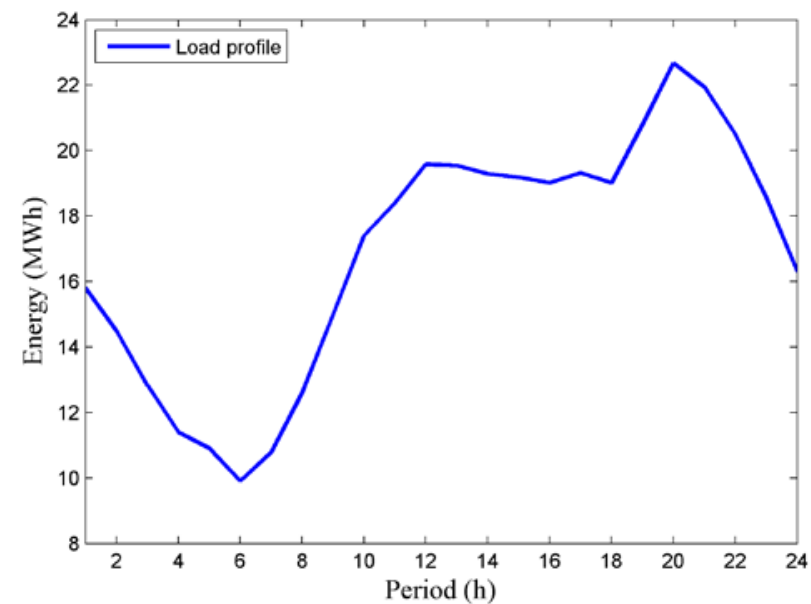

Fig. 3. Profile of the total power consumption in the distribution grid.

\section{EVAluAtion OF Distribution GRID MANAGEMENT}

This section presents a case study that illustrates the application of the proposed models and their respective performance. The presented case study has been chosen to cover a diversity of uncertain situations, allowing demonstration of the proposed model. The simulation was performed with MATLAB and GAMS.

\section{A. Outline}

The case study is partially based on the case study presented in [31]. The original distribution network is presented in [32], while the energy mix in 2050 used for updating the network is proposed in [33]. Fig. 2 shows an 11 $\mathrm{kV}$ distribution network with 37 buses $\left(N_{\text {Bus }}=37\right)$, connected to the high voltage network through two power transformers of 10 MVA each. For simplicity in the analysis of the case study, the DERs are aggregated by technology, so one aggregator represents a specific type of DER technology. However, note 
that the model has been designed to deal with aggregators with a mixed portfolio. In each consumption point $\left(N_{L}=22\right)$, the aggregation of the available DR is also considered. The distribution network supplies energy to 1908 consumers (1850 domestic consumers, 2 industries, 50 commercial stores, and 6 service buildings) [32]. The consumption characteristics in each consumption bus, as well as the consumption profiles of each type of consumer are the same as those used in [31]. Table I summarizes the consumption in each bus. The total load consumption in each period for the distribution network is shown in Fig. 3.

\section{1) DSO Internal Resources}

The DSO is the owner of some equipment installed in the network that supports grid management. Thus transformers with OLTC, capacitor banks and energy storage systems are considered. The general characteristics of the transformers and

TABLE VII: DAY-AHEAD TOTAL OPERATIONS COSTS, FLEXIBILITY AND LOAD SHEDDING FOR A 24-HOUR PERIOD SIMULATION.

\begin{tabular}{l|c|c|c|c}
\hline \hline \multicolumn{1}{c|}{ Model } & Deterministic & $\begin{array}{c}\text { Robust 3 } \\
\text { vert. }\end{array}$ & $\begin{array}{c}\text { Robust 4 } \\
\text { vert. }\end{array}$ & $\begin{array}{c}\text { Robust 6 } \\
\text { vert. }\end{array}$ \\
\hline DG flex (MW) & 1.195 & 1.298 & 1.325 & 1.375 \\
DR flex (MW) & 2.633 & 3.645 & 3.814 & 4.108 \\
Storage (MW) & 0.511 & 0.450 & 0.455 & 0.461 \\
Load shedding (MW) & 0 & 0 & 0 & 0 \\
Flex cost (m.u.) & 23.722 & 23.95 & 24.01 & 24.063 \\
Operating cost (m.u.) & 23.722 & 23.95 & 24.01 & 24.063 \\
\hline \hline
\end{tabular}

TABLE VIII: TOTAL EXPECTED OPERATIONS COSTS; FLEXIBILITY AND LOAD SHEDDING OF 24 HOUR PERIOD SIMULATION AFTER THE VALIDATION PROCESS.

\begin{tabular}{l|c|c|c|c}
\hline \hline \multicolumn{1}{c|}{ Model } & Deterministic & $\begin{array}{c}\text { Robust 3 } \\
\text { vert. }\end{array}$ & $\begin{array}{c}\text { Robust 4 } \\
\text { vert. }\end{array}$ & $\begin{array}{c}\text { Robust 6 } \\
\text { vert. }\end{array}$ \\
\hline DG flex (MW) & 1.192 & 1.229 & 1.250 & 1.314 \\
DR flex (MW) & 2.923 & 3.112 & 3.168 & 3.215 \\
Storage (MW) & 0.116 & 0.167 & 0.237 & 0.270 \\
Load shedding (MW) & 0.698 & 0.421 & 0.273 & 0.130 \\
Flex cost (m.u.) & 23.718 & 23.859 & 23.928 & 23.969 \\
Operating costs (m.u.) & 24.413 & 24.234 & 24.155 & 24.053 \\
\hline
\end{tabular}

capacitor bank are shown in Table II. The on-load tap-changer of the transformers can lead to a maximum deviation in the voltage level of 0.1 p.u. A cost for using tap-changing ability based on [34] is considered, since its use reduces the lifetime and increases the maintenance of the equipment. The capacitor bank tap-changing of reactive power production can reach a maximum reactive power of 0.8 Mvar. As for the transformers, the capacity bank lifetime reduces with the number of changes of the tap position. The cost for tapchanging is based on the formula for capacity bank tapchanging [34]. Throughout the network, energy storage systems with charging and discharging ability are installed. All the ESS equipment has the same characteristics, shown in Table III. The charge $\eta_{C h}$ and discharge $\eta_{D c h}$ efficiency coefficients of storage systems are 0.8 . It is noteworthy that the discharge price incorporates a degradation cost of 0.03 m.u./kWh, based on the study in [30].

\section{2) DER in the Network}

The distribution network considers different aggregators of DER, each representing a different DER. Table IV provides general information on the DER. In addition, the operating point of the DER is given by a previous dispatch from the market.

All DERs are able to provide flexibility based on their generation level. Table $\mathrm{V}$ shows the costs of upward and downward flexibility of the different aggregators. The upward and downward flexibility of CHP, external suppliers and DR go from its level of operating point to its maximum and minimum level of output power, respectively. In addition, it is assumed in the validation stage (real-time simulation with measured data) of the robust solution that the upward and downward flexibility costs increases by $20 \%$ when procured during the validation stage. That is, it is assumed that the realtime activation of these resources is more expensive. The costs for real-time activation, CHP curtailment, renewable spillage and load shedding are shown in Table VI.

The PV and wind power from aggregators are modeled as random variables. Upward and downward flexibility is used according the bids that these aggregators submit to the DSO. The downward flexibility bid is equal to the energy operating point of these aggregators, previously scheduled in the market. The scenarios for wind power generation over the 24-hour periods can be found in [35], [36]. The offering bids were determined for a 24-hour period based on [22]. The use of the constant strategy has been assumed. The constant strategy splits part of the available wind power for energy and upward flexibility [22]. For PV aggregators, a scenario generation based on probability forecasts for short-term production has been performed. The probabilistic forecast was based on the quantile forecast from [37]. These quantiles were used to generate the scenarios and bids. The scenario generation process described in [38] has been used to generate the spatialtemporal trajectories or scenarios. The bids were performed based on the constant approach shown in [22].

A different number of vertices of the uncertainty set $\left(N_{S}\right)$ have been used in this study for comparison of the performance of the methodology, i.e. robust approach with 3 , 4 and 6 vertices has been selected.

\section{B. Results}

\section{1) Day-ahead Solution}

A number of simulations for the robust approach considering a different number of vertices have been performed. The number of vertices collected for building the uncertainty set was based on the efficiency of the methodology in terms of computational performance and solution quality. In contrast, the deterministic simulation is based on the deterministic version of the proposed robust model, where the conditional mean forecast of wind and PV is used as the expected power generation for these resources.

The total operating costs for 24-hour period simulation considering a comparison between the deterministic and robust approach are shown in Table VII. It can be concluded that increasing the number of vertices of the robust optimization approach will generate a more robust solution to the system, which results in a higher cost to the DSO. The high cost of the robust model with 6 vertices is due to reserving more flexibility in the system for some periods. 


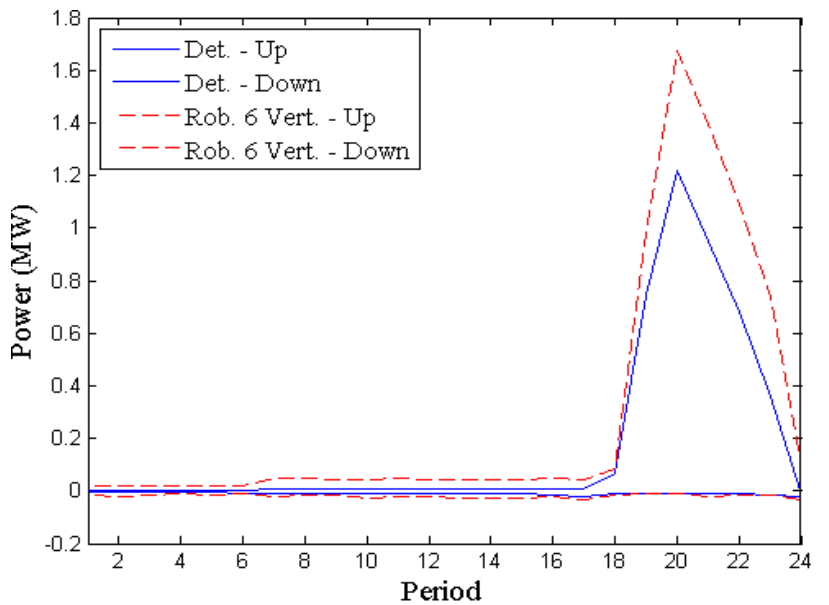

Fig. 4. Contracted flexibility by the DSO under deterministic and robust approach with 6 vertices.

Fig. 4 presents an hourly comparison of the contracted flexibility for upward and downward for all resources (wind, PV, CHP and DR). In general, robust approach reserves a higher level of upward and downward flexibility, since the solution is based on the worst-case solution. Periods 18 to 23 present higher contracted flexibility, since congestion situations are expected in the power transformer and in the network branches.

\section{2) Validation of the Day-ahead Solution}

The validation stage entails performing an hourly optimal power flow considering out-of-sample data of wind and PV and the reserved/contracted flexibilities by the DSO. One hundred new wind and PV realization scenarios have been generated based on the real measurement data, accounting with upward and downward deviations of $20 \%$ from the measurement data.

Besides this, only the flexibility contracted by the DSO to the aggregators can be used during the validation stage. Flexibility contracted is used to solve congestion in the system. In cases where contracted flexibility is not enough to solve the congestion problem, wind and PV curtailment and load shedding are used to balance the system as last resort measures. From this, it is possible to evaluate the robustness of the proposed solution and compare with the traditional deterministic approach. The traditional approach relies on an OPF scheduling based on point forecast information. Table VIII shows the total expected operating costs of each approach after the validation process. One can see that, as expected, the robust approach ensures lower operating costs than the traditional DSO approach (1.07\% more efficient). This is due to the broad flexibility that is scheduled under the worst-case of the robust approach in each hour.

Comparing the results of the traditional and the robust approach under the day-ahead scheduling and during the validation process (Table VII and Table VIII), one can verify that robust approaches reserve more flexibility during the dayahead scheduling that can be used during the validation process, resulting in lower expected operating costs after the validation stage. Thus, in this case study, from a financial point of view, the proposed approach is better than the traditional deterministic DSO approach (present-day practice).
For instance, if the DSO chooses the robust approach instead of the deterministic in the day-ahead market for 0.341 m.u. more (24.063-23.722, Table VII), it would have a saving of 0.360 (24.413-24.053, Table VIII) in the validation stage, which means 0.019 m.u. of net saving.

Although the cost savings are small since the case study is a daily analysis, a yearly analysis can represent a significant saving for the DSO. However, it is possible that a different case study may show distinct behavior. That is, in cases with low levels of uncertain production and congestion problems, robust approach may be more expensive and therefore perform poorer than the traditional approach, yet ensuring high levels of system reliability. Additionally, the proposed approach also ensures higher reliability by requiring less load shedding than the traditional approach.

The behavior of the deterministic approach under the validation process for the 24-hour period is illustrated in Fig. 5 a). The blue area represents the flexibility contracted at the day-ahead stage, while the red area shows the load shedding used by the deterministic approach during the validation. The green line represents the total power used by the DSO to manage the grid during the validation process, while the blue line shows the flexibility used by the deterministic approach during the validation process. One can see that the flexibility contracted in the day-ahead is not enough to solve the congestion problem that occurred during the real-time operation. Thus, load shedding is used by the DSO to manage this congestion.

Fig. $5 \mathrm{~b}$ ) depicts the behavior of the proposed approach under the validation process. One can see that, in most of the periods, the contracted flexibility is more than enough to solve congestion problems that occur during real-time operation. However, between 17 and 18 periods, there is a need for extra power to solve congestion. Thus, load shedding is used to manage the congestion, accounting for a high penalty.

Comparing the results of the deterministic - Fig. 5 a) - and proposed - Fig. 5 b) - approaches, one can identify different behavior and portions of the scheduled and used flexibility. The proposed approach reserves more flexibility than the deterministic approach, which is useful during the real-time operation. Thus, the proposed approach infers less operating costs than the equivalent deterministic approach after the validation process due to the lower need of load shedding (extremely expensive) to manage congestion in the system.

In more detail, the difference between the expected operating costs of the deterministic and robust approaches is illustrated in Fig. 6. From the cumulative distribution function it is possible to evaluate the probability of the scenarios occurring in a range of expected operating costs. For instance, an expected operating cost of up to $24.148 \mathrm{~m}$.u. is expected to happen in $80 \%$ of the scenarios for the robust 6 vertices approach, while the same cost is most likely to occur in $14.69 \%$ of the scenarios for the deterministic approach. This highlights the effectiveness of the proposed approach to the problem. In more detail, the horizontal axis of Fig. 6 covers less than 1 m.u. because the model considers that the regulation of reactive power by the DG is mandatory and nonremunerated, and therefore the regulation of capacitor bank is not used in the present case study. Additionally, one can see that there is always need for flexibility, and therefore the 



Fig. 5. Contracted, used flexibility and load shedding (in expectation) over 24-hour for a) deterministic and b) robust (6 vertices) approaches under real-time operation.

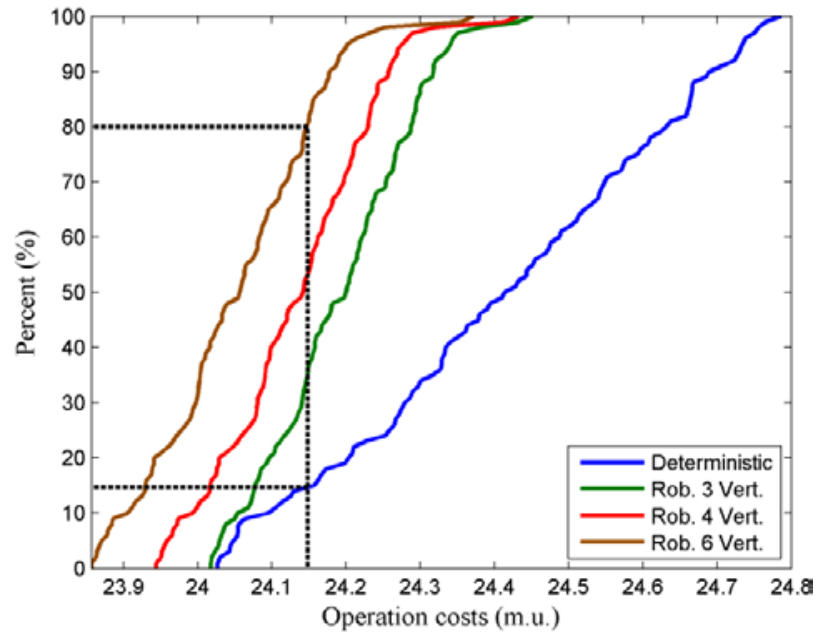

Fig. 6. Empirical cumulative distribution function of expected operating costs for deterministic (blue line), robust 3 vertices (green line), robust 4 vertices (red line) and robust 6 vertices (brown line) approaches.

deterministic approach presents worse results than robust approaches. Moreover, it is noteworthy that the proposed methodology allows the DSO to control the number of vertices, thereby to some extent controlling the robustness of the obtained solution. Still, this is a heuristic method to solve the problem which does not guarantee to find the global optima and therefore the most robust solution.

\section{3) Computational Performance}

The computations were carried out with DICOPT [39] as an MINLP solver on an Intel Core i5 $2.70 \mathrm{GHz}$ processor with 8 GB RAM. All modeling was performed in the GAMS [40] modeling language. The deterministic approach was performed for 8 minutes, while the robust 3, 4 and 6 vertices were performed for $2.5 \mathrm{~h}, 6.4 \mathrm{~h}$ and $16.2 \mathrm{~h}$, respectively. The robust approach takes a high computational time to converge, due to the complexity of the proposed formulation.

One way of reducing the complexity of the methodology is through linearization of the nonlinearity. In this way, the AC OPF can be formulated in the format of a second-order cone programming [41] or semidefinite programming [42], which are convex models that can be efficiently solved. However, these models usually give approximate solutions for the nonlinear solution. Improved methods, such as strong secondorder cone programming relaxations based on McCormick relaxation to improve the approximation of the convex region of bilinear constraints have been emerging. Such advanced methods, reduce the optimality gap in relation to the traditional nonlinear models [43]. Other recent developments in AC OPF can be found in [13].

On the other hand, the computational performance can also be improved by considering different optimization algorithms, such as meta-heuristics. These optimization algorithms are somehow able to provide approximate solutions of the AC OPF problem, requiring less computational effort to solve the problem [44].

Nevertheless, a combination of reducing the complexity of the problem through mathematical optimization techniques and the use of meta-heuristics to improve the computational performance is the most likely evolution for the proposed methodology.

\section{CONCLUSIONS}

Increasing the flexibility of DER will allow the DSO to reserve this flexibility to handle local technical problems in the distribution system, thereby, improving security of supply.

This work proposes a new method for DSO distribution grid management under spatial-temporal uncertainty. It is assumed that the DSO applies a preventive approach on grid management by reserving flexibility from DER at the dayahead stage. The results show that such an approach is more expensive than present-day practice at the day-ahead stage, but cheapest on the operating day, i.e. the robust approach provides savings in the DSO operating costs by reserving some flexibility at the day-ahead stage to be used during realtime operation, avoiding extra penalties. In addition, results show that the level of robustness depends on the modeling of the uncertainty set, i.e. the number of vertices of the uncertainty set to use in the optimization process. However, the price of robustness is paid in the computational effort. An important conclusion from this work is that robust solutions increase the reliability of the distribution system, representing a preventive approach for grid management. 
Nevertheless, the use of this methodology by the DSO requires a yearly evaluation between the costs saved by this approach and its usefulness (perhaps, measured by the number of events in a year where the method is useful). Thus, future work should focus on this trade-off, as well as on improving the computational performance of the optimization algorithm, potentially by combining meta-heuristics with mathematical optimization techniques to assure tractable, robust solutions.

\section{APPENDIX}

The general adaptive robust optimization for a single period is formulated as the following three-level optimization problem:

$$
\begin{array}{r}
\min _{x} C^{D A} x+\max _{u} \min _{y} C_{t}^{R T} y \\
\text { s.t. } T x+H y=u: \lambda, \\
y \geq 0 \quad: \mu, \\
\text { s.t. } u \in W
\end{array}
$$

s.t. $A x \leq a$,

$$
x \geq 0 \text {, }
$$

where $T$ and $H$ are matrices defining the left-hand-side of recourse constraints, $\lambda$ and $\mu$ are vectors of Lagrange multipliers associated with equalities and inequalities constraints of recourse stage. $A$ is a matrix defining the lefthand-side of first stage constraints and $a$ is a vector defining the right-hand-side of first stage constraints.

Considering that the optimization problem from (5) cannot be solved directly given its min-max-min structure, the inner minimization problem can be replaced by its dual formulation. Thus, the optimization problem assumes the form of

$$
\begin{gathered}
\min _{x} C^{D A} x+\max _{u} \max _{y}(u-T x)^{T} \lambda \\
\text { s.t. } H^{T} y+\mu=C^{R T}, \\
\mu \geq 0, \\
u \in W
\end{gathered}
$$

s.t. $A x \leq a$,

$x \geq 0$,

The two-level formulation in (6) is more complex due to the presence of the bilinear term arising as the product of the dual variable $\lambda$ and the uncertain parameter $u$ in the objective function. However, following the proof on [23] the optimal solution will be at one of the vertices of the polyhedral uncertainty set $W$. In addition, the vector $x$ of first stage variables do not appear in the constraints of the single maximization problem, so the feasible polyhedral is independent of the first stage decisions, thereby it has a finite number of vertices $s=1, \ldots, N_{s}$. Thus a variable $\beta$ representing the worst-case recourse cost can be added to the model, replacing the max-max problem, such as

$$
\begin{array}{ll}
\min _{x} C^{D A} x+\beta & \\
\text { s.t. } \beta \geq C^{R T} y_{s} & \forall s \in\left\{1, \ldots, N_{s}\right\}, \\
T x+H y_{s}=u_{s} & \forall s \in\left\{1, \ldots, N_{s}\right\},
\end{array}
$$

$$
\begin{aligned}
& y_{s} \geq 0 \\
& A x \leq a, \\
& x \geq 0,
\end{aligned}
$$

where all the recourse constraints (7b) to (7d) are listed for all vertices $s$ of the uncertainty set.

\section{ACKNOWLEDGEMENT}

The authors would like to acknowledge the editor and the reviewers for their in-depth and detailed comments as well as valuable suggestions. They also thank Jalal Kazempour for giving valuable suggestions for the paper.

\section{REFERENCES}

[1] T. Ackermann, G. Andersson, and L. Söder, "Distributed generation: A definition,” Electr. Power Syst. Res., vol. 57, no. 3, pp. 195-204, 2001.

[2] I. J. Pérez-Arriaga, S. Ruester, S. Schwenen, C. Battle, and J.-M. Glachant, "From distribution networks to smart distribution systems: rethinking the regulation of european electricity DSOs,” THINK project, 2013. [Online]. Available:

http://www.eui.eu/projects/think/documents/thinktopic/topic12digital.pd f.

[3] Eurelectric, “Active distribution system management: a key tool for the smooth integration of distributed generation,” Eurelectric, 2013. [Online]. Available:

http://www.eurelectric.org/media/74356/asm_full_report_discussion_pa per_final-2013-030-0117-01-e.pdf.

[4] D. Six, A. Ramos, and E. R. Puente, "Evaluation of current market architectures and regulatory frameworks and the role of DSOs," Deliverable D1.2, European Project evolvDSO, 2014. [Online]. Available: http://www.evolvdso.eu/Home/Results.

[5] D. Bertsimas, E. Litvinov, X. A. Sun, J. Zhao, and T. Zheng, “Adaptive robust optimization for the security constrained unit commitment problem,” IEEE Trans. Power Syst., vol. 28, no. March, pp. 1-8, 2013.

[6] M. Zugno and A. J. Conejo, “A robust optimization approach to energy and reserve dispatch in electricity markets,” Eur. J. Oper. Res., vol. 247, no. 2, pp. 659-671, 2015.

[7] M. Bazrafshan and N. Gatsis, "Decentralized stochastic optimal power flow in radial networks with distributed generation,” IEEE Trans. Smart Grid, vol. 8, no. 2, pp. 787-801, 2017.

[8] Y. P. Agalgaonkar, B. C. Pal, and R. A. Jabr, "Stochastic distribution system operation considering voltage regulation risks in the presence of PV generation,” IEEE Trans. Sustain. Energy, vol. 6, no. 4, pp. 13151324, 2015

[9] C. S. Saunders, "Point estimate method addressing correlated wind power for probabilistic optimal power flow," IEEE Trans. Power Syst., vol. 29, no. 3, pp. 1045-1054, 2014.

[10] R. A. Jabr, “Adjustable robust OPF with renewable energy sources," IEEE Trans. Power Syst., vol. 28, no. 4, pp. 4742-4751, 2013.

[11] Y. Zhang and G. B. Giannakis, "Robust optimal power flow with wind integration using conditional value-at-risk," in IEEE International Conference on Smart Grid Communications (SmartGridComm), 2013, pp. 654-659.

[12] X. Bai, L. Qu, and W. Qiao, "Robust AC optimal power flow for power networks with wind power generation,” IEEE Trans. Power Syst., vol. 31, no. 5, pp. 4163-4164, 2016.

[13] F. Capitanescu, "Critical review of recent advances and further developments needed in AC optimal power flow,” Electr. Power Syst. Res., vol. 136, pp. 57-68, 2016.

[14] H. Abdi, S. D. Beigvand, and M. La Scala, “A review of optimal power flow studies applied to smart grids and microgrids,” Renew. Sustain. Energy Rev., pp. 1-25, 2016.

[15] A. Ulian, M. Sebastian, G. Bartolucci, and C. Gutshi, "Business use cases definition and requirements,” Deliverable D2.1, EU Project evolvDSO, 2014. [Online]. Available: http://www.evolvdso.eu/Home/Results

[16] A. I. Chrysochos, G. C. Kryonidis, E. O. Kontis, C. S. Demoulias, and G. K. Papagiannis, "Dynamic equivalent models for the simulation of controlled DRES,” Deliverable D, 2014. [Online]. Available: http://www.project-increase.eu/index.php?cmd=s\&id=74.

[17] A. Madureira, R. Bessa, J. Meirinhos, D. Fayzur, J. Filipe, A. A. 
Messias, D. A. Lopes, and P. G. Matos, "The impact of solar power forecast errors on voltage control in smart distribution grids," in 23rd International Conference on Electricity Distribution (CIRED 2015), Lyon, France, 2015.

[18] J. Tastu, P. Pinson, and H. Madsen, "Space-time trajectories of wind power generation: Parameterized precision matrices under a Gaussian copula approach,” in Modeling and Stochastic Learning for Forecasting in High Dimensions, vol. 217, Springer, 2015, pp. 267-296.

[19] G. Michalke and A. D. Hansen, "Grid support capabilities of wind turbines," in Handbook of Wind Power Systems, Springer, 2014, pp. 569-590.

[20] K. Knorr, B. Zimmermann, D. Kirchner, M. Speckmann, R. Spieckermann, M. Widdel, M. Wunderlich, R. Mackensen, K. Rohrig, F. Steinke, P. Wolfrum, T. Leveringhaus, T. Lager, L. Hofmann, D. Filzek, T. Göbel, B. Kusserow, L. Nicklaus, and P. Ritter, "Kombikraftwerk 2 final report,” 2014. [Online]. Available:

http://www.kombikraftwerk.de/fileadmin/Kombikraftwerk_2/English/K ombikraftwerk2 FinalReport.pdf.

[21] Windvision, Enercon, Eneco, and Elia, "Delivery of downward aFRR by wind farms,” 2015. [Online]. Available:

http://www.elia.be/ /media/files/Elia/users-group/task-forcebalancing/Downward_aFRR_windfarms_EN_2015.pdf.

[22] T. Soares, P. Pinson, T. V. Jensen, and H. Morais, "Optimal offering strategies for wind power in energy and primary reserve markets," IEEE Trans. Sustain. Energy, vol. 7, no. 3, pp. 1-10, 2016.

[23] J. M. Morales, A. J. Conejo, H. Madsen, P. Pinson, and M. Zugno, "Integrating renewables in electricity markets - operational problems," Springer, vol. 205, p. 429, 2014.

[24] Y. Guan and J. Wang, "Uncertainty sets for robust unit commitment," IEEE Trans. Power Syst., vol. 29, no. 3, pp. 1439-1440, 2014.

[25] C. B. Barber, D. P. Dobkin, and H. Huhdanpaa, "The quickhull algorithm for convex hulls,” ACM Trans. Math. Softw., vol. 22, no. 4, pp. 469-483, 1996.

[26] D. H. Douglas and T. K. Peucker, "Algorithms for the reduction of the number of points required to represent a digitized line or its caricature," Cartogr. Int. J. Geogr. Inf. Geovisualization, vol. 10, no. 2, pp. 112-122, 1973.

[27] J. Hershberger and J. Snoeyink, "Speeding up the Douglas-Peucker linesimplification algorithm," in 5th International Symposium on Spatial Data Handling, 1992, pp. 134-143.

[28] H. Haghighat and S. W. Kennedy, "A model for reactive power pricing and dispatch of distributed generation," in IEEE PES General Meeting, Minneapolis, US, 2010, pp. 1-10.

[29] ERSE, "Despacho nº 7253/2010," Diário da República [in Portuguese], 2010. [Online]. Available:

http://www.erse.pt/pt/legislacao/Legislacao/Attachments/1411/Despacho 7253_2010.pdf.

[30] S. B. Peterson, J. F. Whitacre, and J. Apt, "The economics of using plugin hybrid electric vehicle battery packs for grid storage," J. Power Sources, vol. 195, no. 8, pp. 2377-2384, 2010.

[31] H. Morais, T. Sousa, J. Soares, P. Faria, and Z. Vale, "Distributed energy resources management using plug-in hybrid electric vehicles as a fuel-shifting demand response resource,” Energy Convers. Manag., vol. 97, pp. 78-93, 2015.

[32] R. N. Allan, R. Billinton, I. Sjarief, L. Goel, and K. S. So, “A reliability test system for educational purposes - basic distribution-system data and results,” IEEE Trans. Power Syst., vol. 6, no. 2, pp. 813-820, 1991.

[33] European Climate Foundation, "Roadmap 2050: A practical guide to a prosperous, low-carbon Europe - technical analysis,” Europe, 2010. [Online]. Available:

http://www.roadmap2050.eu/attachments/files/Volume1_fullreport_Pres sPack.pdf.

[34] Y. J. Zhang and Z. Ren, "Optimal reactive power dispatch considering costs of adjusting the control devices," IEEE Trans. Power Syst., vol. 20, no. 3, pp. 1349-1356, 2005.

[35] P. Pinson, "Wind energy: forecasting challenges for its operational management," Stat. Sci., vol. 28, no. 4, pp. 564-585, 2013.

[36] W. A. Bukhsh, C. Zhang, and P. Pinson, "Data for stochastic multiperiod opf problems.” [Online]. Available: https://sites.google.com/site/datasmopf/.

[37] R. J. Bessa, A. Trindade, and V. Miranda, "Spatial-temporal solar power forecasting for smart grids," IEEE Trans. Ind. Informatics, vol. 11, no. 1, pp. 232-241, 2015.

[38] P. Pinson, H. Madsen, H. A. Nielsen, G. Papaefthymiou, and B. Klöckl, "From probabilistic forecasts to statistical scenarios of short-term wind power production,” Wind Energy, vol. 12, no. 1, pp. 51-62, 2009.

[39] A. Vecchietti, I. Grossmann, R. Raman, and E. Kalvelagen, "DICOPT solver," Carnegie Mellon Univ. GAMS Dev. Corp., 2008.

[40] R. Rosenthal, GAMS - a user's guide. Washington, DC: GAMS Development Corporation, 2008.

[41] M. S. Lobo, L. Vandenberghe, S. Boyd, and H. Lebret, "Applications of second-order cone programming,” Linear Algebra Appl., vol. 284, no. 1-3, pp. 193-228, 1998.

[42] S. H. Low, "Convex relaxation of optimal power flow - Part I: formulations and equivalence," IEEE Trans. Control Netw. Syst., vol. 1, no. 1, pp. 15-27, 2014.

[43] B. Kocuk, S. S. Dey, and X. A. Sun, "Strong SOCP Relaxations for the Optimal Power Flow Problem,” Oper. Res., pp. 1-20, 2016.

[44] S. Frank, I. Steponavice, and S. Rebennack, "Optimal power flow: a bibliographic survey II,” Energy Syst., vol. 3, no. 3, pp. 259-289, 2012.

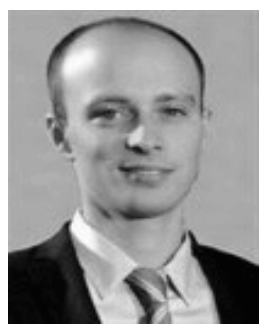

Tiago Soares received the M.Sc. degree in electrical engineering from the School of Engineering of Polytechnic Institute of Porto, Porto, Portugal (ISEP) in 2013 and the Ph.D. degree in electrical engineering from the Technical University of Denmark in 2017.

He is a postdoc at the Technical university of Denmark, Centre for Electric Power and Energy, Department of Electrical Engineering.

His research interests include electricity markets, distributed generation, energy resources management and optimization, optimization under uncertainty and future power systems.

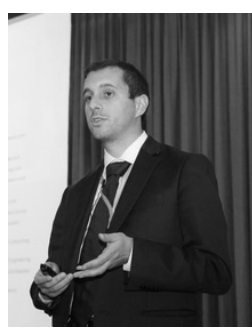

Ricardo J. Bessa received his Licenciado (fiveyear) degree from the Faculty of Engineering of the University of Porto, Portugal (FEUP) in 2006 in Electrical and Computer Engineering. In 2008, he received the M.Sc. degree in Data Analysis and Decision Support Systems on the Faculty of Economics of the University of Porto (FEP). He obtained his Ph.D. degree in the Doctoral Program in Sustainable Energy Systems (MIT Portugal) at FEUP in 2013. Currently, he is a Senior Researcher and Area Manager at INESC TEC in its Center for Power and Energy Systems. His research interests include renewable energy, energy analytics, smart power systems and electricity markets. He worked in several international projects, such as the European Projects FP6 ANEMOS.plus, FP7 SuSTAINABLE, FP7 evolvDSO, Horizon 2020 UPGRID, and an international collaboration with Argonne National Laboratory for the U.S. Department of Energy.



Pierre Pinson (M'11--SM'13) received the M.Sc. degree in applied mathematics from the National Institute for Applied Sciences (INSA Toulouse, France) and the Ph.D. degree in energetics from Ecole des Mines de Paris (France). He is a Professor at the Technical University of Denmark (DTU), Centre for Electric Power and Energy, Department of Electrical Engineering, also heading a group focusing on Energy Analytics \& Markets. His research interests include among others forecasting, uncertainty estimation, optimization under uncertainty, decision sciences, and renewable energies. Prof. Pinson acts as an Editor for the International Journal of Forecasting, and for Wind Energy.



Hugo Morais (S'08-M'11) is a researcher in the Mesures et système d'Information des Réseaux Electriques Group at the Électricité de France, Saclay, France. His research interests include distributed energy resources management, virtual power players, smart grids, and future power systems, agents technology and power systems visualization. Morais has a $\mathrm{PhD}$ in electrical engineering from the University of Trás-os-Montes e Alto Douro. 